International Conference on Renewable Energies and Power Quality (ICREPQ'11)

Las Palmas de Gran Canaria (Spain), 13th to 15th April, 2011

\title{
Artificial Intelligence Techniques based on aquaculture solar thermal water heating system control
}

\author{
Doaa M. Atia ${ }^{1}$, Faten H. Fahmy ${ }^{1}$, Ninet M. Ahmed ${ }^{1}$, and Hassen T. Dorrah ${ }^{2}$ \\ ${ }^{1}$ Photovoltaic Cell Department \\ Electronic Research Institute \\ Cairo, Egypt \\ Phone/Fax number: +202 33351631, Email : doaa_matia@yahoo.com \\ ${ }^{2}$ Departments of Electrical Power and Machines, \\ Faculty of Engineering, Cairo University \\ Cairo, Egypt
}

\begin{abstract}
The One of the most promising applications of hot water is aquaculture. Temperature is one of the most principle parameters affects aquaculture life. It can cause stress and mortality or superior environment for growth and reproduction. Shrimp is warm water aquaculture type need hot water supply. To increase pond production it is necessary to keep water temperature at $34 \mathrm{oC}$. Artificial intelligence (AI) techniques are becoming useful as alternate approaches to conventional techniques or as components of integrated systems. They have been used to solve complicated practical problems in various areas and are becoming more and more popular nowadays. In this paper a control system using artificial neural network control (NNC) either adaptive fuzzy logic control (AFLC) are design to control the hot water temperature. A comparison study is applied between the performance of FLC and NNC. The performance of NNC is the best because the control design takes into consideration different variables which give an accurate output than FLC. Also this paper introduces a complete mathematical modeling and MATLAB SIMULINK model for the proposed aquaculture heating system.
\end{abstract}

\section{Key words}

aquaculture, forced circulation hot water system, Artificial intelligence (AI) techniques, neural networks control, fuzzy logic control.

\section{Introduction}

Recently Intensive aquaculture is a modern cultivation way because it develops fast in many countries. Today, People pay more and more attention on aquaculture for its advantages of high yield, no-time-limit, low-feed and high-utilization of water and renewable energy sources [1]. The purpose for applying process control technology to aquaculture in developed countries encompasses many socioeconomic factors, including variable climate.
Anticipated benefits for aquaculture process control systems are to be increased process efficiency, reduced energy and water losses, reduced labor costs, reduced stress and disease, improved accounting, improved understanding of the process [2].

The study of artificial neural networks (ANN) and fuzzy logic control (FLC) are the two major branches of intelligence control, which is based on the concept of artificial intelligence (AI). AI can be defined as computer emulation of the human thinking process. During the last ten years, there has been a substantial increase in the interest on artificial neural networks. During the last ten years, there has been a substantial increase in the interest on artificial neural networks. Specifically, they are good for tasks involving incomplete data sets, fuzzy or incomplete information and for highly complex and illdefined problems, where humans usually decide on an intuitional basis [3-5]. In this paper the mathematical modeling of solar thermal water heating system for aquaculture pond is suggested and control of water temperature of aquaculture system is achieved using AI techniques. Finally a comparison study is applied between the performance of FLC and NNC.

\section{Proposed Aquaculture System}

The proposed system consists of solar collector unit to supply hot water during the day hours, biogas heater as auxiliary unit during night and cloudy days, storage tank to keep water temperature at high degree, thermostatic valve to control hot water flow rate to the pond. As depicted in Fig. 1. 


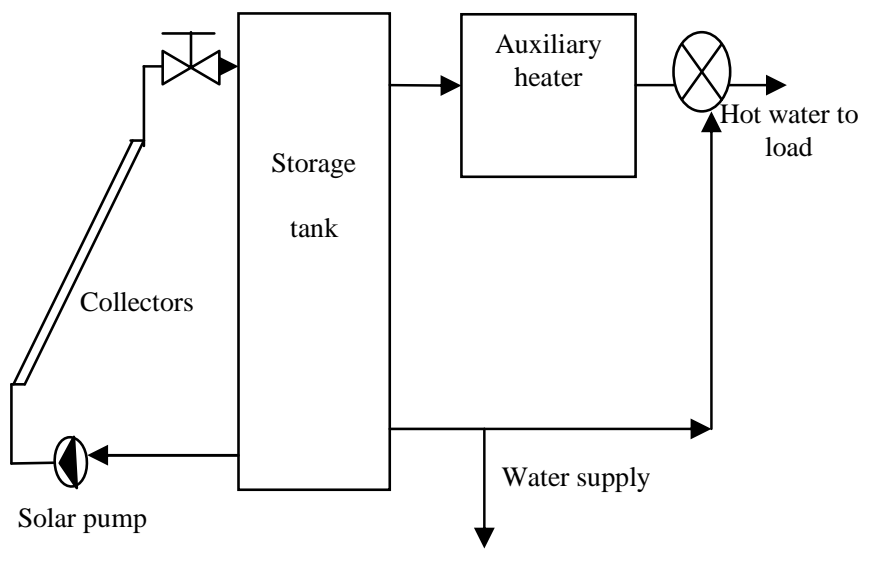

Fig. 1 Schematic of a solar water heating system.

\section{Mathematical Model of Aquaculture Solar Thermal System}

Storage tank temperature is an important parameter which influences the system size and performance. Energy balance of a well mixed storage tank can be expressed as [6]

$$
\rho V_{s} c_{p} \frac{d T_{t s}}{d t}=q_{c}-q_{l}-q_{s t l}
$$

Where $\rho$ water density $\left(\mathrm{Kg} / \mathrm{m}^{3}\right), \mathrm{Vs}$ is is storage tank volume $\left(\mathrm{m}^{3}\right)$, Tts is storage tank temperature $\left({ }^{\circ} \mathrm{C}\right), \mathrm{Cp}$ is specific heat of water $\left(4190 \mathrm{~J} / \mathrm{Kg}{ }^{\circ} \mathrm{C}\right)$, qc is actual useful energy gain, $\mathrm{q}_{1}$ is load energy, and qstl is storage tank losses.

\section{A. Flat Plate Collector Modeling}

Solar useful heat gain rate $\left(\mathrm{q}_{\mathrm{c}}\right)$ from the collector array is calculated by

$$
q_{c}=F_{R} A_{c}\left[\alpha \tau G-U_{l}\left(T_{i}-T_{a}\right)\right]^{+}
$$

Where qc represents actual useful energy gain $(\mathrm{W})$, FR the collector heat removal factor, $G$ intensity of solar radiation, in $\left(\mathrm{W} / \mathrm{m}^{2}\right), A_{c}$ collector surface area $\left(\mathrm{m}^{2}\right),(\alpha \tau)$ is the transmittance absorptance product, $U_{l}$ is collector overall heat transfer coefficient $\left(\mathrm{W} / \mathrm{m}^{2}{ }^{\circ} \mathrm{C}\right), \mathrm{Ta}$ is the ambient temperature $\left({ }^{\circ} \mathrm{C}\right)$, and $T_{i}$ is the initial temperature. Where + sign indicates that only positive values of $q_{c}$ is considered in the analysis. This implies that hot water from the collector enters the tank only when solar useful heat gain becomes positive [6].

\section{B. Mathematical modelling of the aquaculture pond}

A numerical model based on energy balance was developed to simulate the thermal behavior of the openpond system. Assumed uniform temperature for the entire pond, and thus applied a well-mixed model [7].

\section{Evaporation Losses}

The evaporation heat loss is the largest loss component and is given

$$
q_{e}=A_{p} P_{a}\left[35 V+43\left(T_{p}-T_{a}\right)^{1 / 3}\right\rfloor\left(\omega_{p}-\omega_{a}\right)
$$

Where $q_{e}$ is the evaporation loss $(\mathrm{W}), V$ is the wind speed in $(\mathrm{m} / \mathrm{s})$ in the vicinity of the pond, $P_{a}$ the ambient air pressure $(101.3 \mathrm{k} \mathrm{Pa}) . T_{P}$ is the pond temperature, $T_{a}$ is the ambient temperature, $\omega_{P}$ is the saturation humidity ratio at the pond temperature, $\omega_{a}$ is the humidity ratio of the ambient air above the pond, $A_{p}$ is the area of the pond $[7,8]$.

\section{Convection Losses}

Heat losses due to convection to the ambient air can be expressed as $[7,8]$

$$
q_{c}=q_{e} \times 0.0006 \frac{T_{p}-T_{a}}{\omega_{p}-\omega_{a}}
$$

\section{E. The Net Radiation Losses}

Results from the surface of the pond to the sky which can be expressed as $[7,8]$ :

$$
q_{r}=\mathcal{E} \sigma A\left[\left(T_{p}+273\right)^{4}-T_{s}{ }^{4}\right](5)
$$

Where qr is the radiation loss, $\varepsilon$ is the emissivity of the surface, $\sigma$ is the Stefan-Boltzmann constant, TS is the sky temperature in degrees Kelvin, $\mathrm{Tp}$ is the pond temperature.

\section{F. Solar Radiation Heat Gain}

Heat gain due to the absorption of solar radiation by the pond is given by $[6,7]$

$$
q_{s}=\alpha A G
$$

Where $\alpha$ is pond absorptance (0.9).

\section{G. The Control Thermostatic Valve Modeling}

The required characteristic of this valve must be linear, such that controlling the valve input signal, will directly control the mass flow rate of water. Therefore, the transfer function of the used valve will be considered to be a first order one, as

$$
G_{v}(s)=\frac{1}{s+1}
$$

\section{Artificial Intelligence Control Techniques}

\section{AFLC algorithm}

Fuzzy logic controller (FLC) techniques have been found to be a good replacement for conventional control 
techniques, owing to their low computational burden and ease of implementation using microcomputers [8]. The fuzzy-logic based controller overcomes system ambiguities and parameter variations by modeling the control objective based on a human operator experience, common sense, observation and understanding how the system responses, thereby eliminating the need for an explicit mathematical model for the system dynamics[9]. Fuzzy Logic Controller (FLC) In the last few years, fuzzy logic has met a growing interest in many control applications due to its non-linearity handling features and independence of the plant modeling. The fuzzy controller (FLC) operates in a knowledge-based way, and its knowledge relies on a set of linguistic if-then rules, like a human operator.

\section{A. AFLC control structure}

Fuzzy logic systems are widely used for control, system identification, and pattern recognition problems. Fuzzy set theory generalizes classical set theory in that the membership degree of an object to a set is not restricted to the integers 0 and 1 , but may take on any value in $[0,1]$. By elaborating on the notion of fuzzy sets and fuzzy relations we can define fuzzy logic systems (FLS). FLSs are rulebased systems in which an input is first fuzzified (i.e., converted from a crisp number to a fuzzy set) and subsequently processed by an inference engine that retrieves knowledge in the form of fuzzy rules contained in a rule-base. The fuzzy sets computed by the fuzzy inference as the output of each rule are then composed and defuzzified (i.e., converted from a fuzzy set to a crisp number). A fuzzy logic system is a nonlinear mapping from the input to the output space. A schematic representation of a FLS is presented in Fig. 2. The operation of a FLS is based on the rules contained in the rule base [9-11].

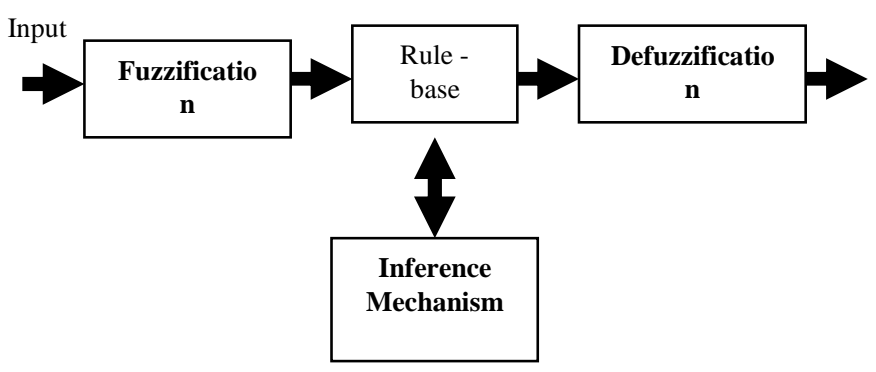

Fig. 2 Fuzzy controller architecture.

\section{B. Advantages of AFLC control [11]}

- $\quad$ Based on intuition and judgment.

- No need for a mathematical model.

- Provides a smooth transition between members and nonmembers.

- Relatively simple, fast and adaptive.

- Less sensitive to system fluctuations.

- Can implement design objectives, difficult to express mathematically, in linguistic or descriptive rules.

\section{Neural network control algorithm}

Neural networks are massively parallel processors that have the ability to learn patterns through a training experience. Traditionally, modeling of equipment and controller algorithms consists of computer programs that rely on complicated mathematics tailored for a specific application, and are generally not portable to other systems. An alternative to traditional models is through the use of neural networks (NN), from a branch of artificial intelligence. Neural networks are nonlinear computer algorithms that learn with feedback, and can model the behavior of complicated nonlinear processes. Within pattern association networks there are many types of configurations, each with a specific architecture useful for solving different types of problems. In all cases, however, the goal is to map input to output while minimizing an error function. Nodes in each of the other layers collect information from the weighted upstream node outputs (usually by summation) and process the information with an activation function. A value computed from the activation function is then available to be sent to the next layer using more weights [12-16].

\section{A. Threshold Logic Unit}

A simple model of a biological neuron is the so called the threshold logic unit (TLU), shown in Fig. 3. The TLU is also called the perceptron. A TLU is parameterized by a set of weights and a threshold (bias). The summation operation is followed by the sign activation function,

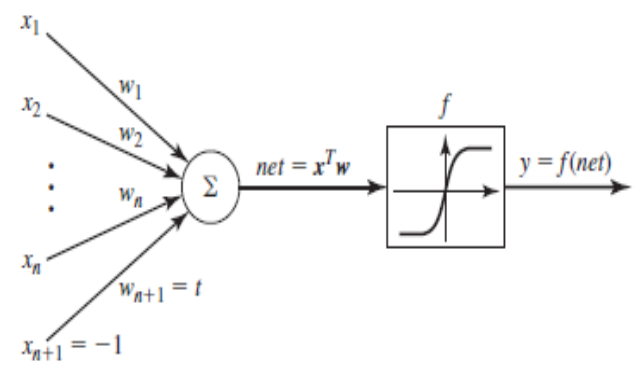

Fig. 3 single perceptron with a differentiable sigmoidal activation function.

\section{B. Advantages of NN control}

- Input output mapping.

- Adaptive.

- Parallel distribution.

- Used in incomplete data set.

- Used in nonlinear problem.

- ANN has the ability to handle large and complex systems with many interrelated parameters.

- Artificial neural networks differ from traditional simulation approaches in that they are trained to learn solutions rather than being programmed to model a specific problem in the normal way. 


\section{The Error Back-Propagation Algorithm}

The most popular supervised training algorithm is the one named 'error back-propagation', or simply 'backpropagation'. It involves training a FFANN structure made up of activation function neurons. The back-propagation algorithm is a gradient method aiming to minimize the total operation error of the neural network. The process is intended to minimize the Error between the network output and the output actual output for the same input. The total error is a function defined by

$$
R M S=\frac{1}{2} \sum_{j}\left|t_{j}-o_{j}\right|^{2}
$$

Where $t$ is target value, and o is output value [12-16].

\section{Proposed Control System}

The AI control is utilized to provide the system with the required control action. The control signal is used to control the operation of thermostatic valve to control the hot water flow rate added to the pond to keep water temperature constant at $34 \mathrm{oC}$ as depicted in Fig.4.

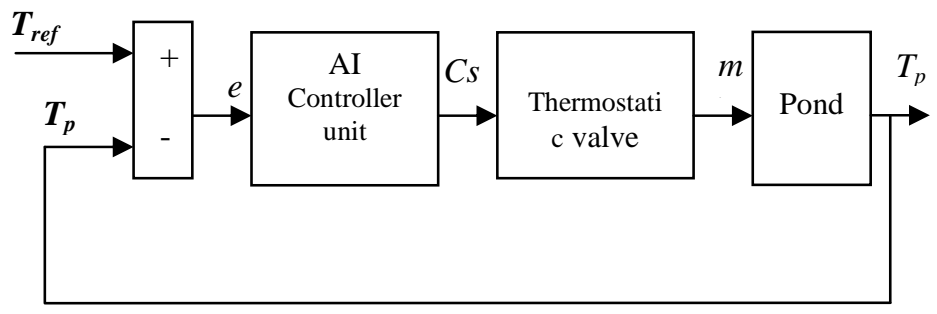

Fig. 4 Block diagram AI control for pond water temperature.

\section{A. AFLC system design}

Fuzzy logic control offers a way of dealing with modeling problems by implementing linguistic. Table I shows possible control rule base which are used. The rows represent the rate of the error change (ce) and the columns represent the error (e). Each pair (e, ce) determines the output level from NL to PL corresponding to output. Here NL is negative big, NM is negative medium, NS is negative small, $\mathrm{Z}$ is zero, PS is positive small, PM is positive medium and PL is positive big. The corresponding membership functions are depicted in Fig. 5. The continuity of input membership functions, reasoning method, and defuzzification method for the continuity of the mapping ufuzzy $\left(\mathrm{e}, \mathrm{e}^{\cdot}\right)$ are necessary. In this paper, the triangular membership function, the max-min reasoning method, and the center of gravity defuzzification method are used, as those methods are most frequently used in many literatures. Figure 6 shows the MATLAB SIMULINK of FLC system.
TableI- Rule Base Of Fuzzy Logic Controller.

\begin{tabular}{|c|c|c|c|c|c|c|c|}
\hline $\begin{array}{c}\text { ce } \\
\text { e }\end{array}$ & NL & NM & NS & Z & PS & PM & PL \\
\hline NL & NL & NL & NL & NL & NS & NS & Z \\
\hline NM & NL & NL & NL & NM & NS & Z & PS \\
\hline NS & NL & NL & NL & NS & Z & PS & PS \\
\hline $\mathbf{Z}$ & NL & NM & NS & Z & PS & PM & PL \\
\hline PS & NS & NS & Z & PS & PL & PL & PL \\
\hline PM & NS & Z & PS & PM & PL & PL & PL \\
\hline PL & $\mathbf{Z}$ & PS & PS & PL & PL & PL & PL \\
\hline
\end{tabular}

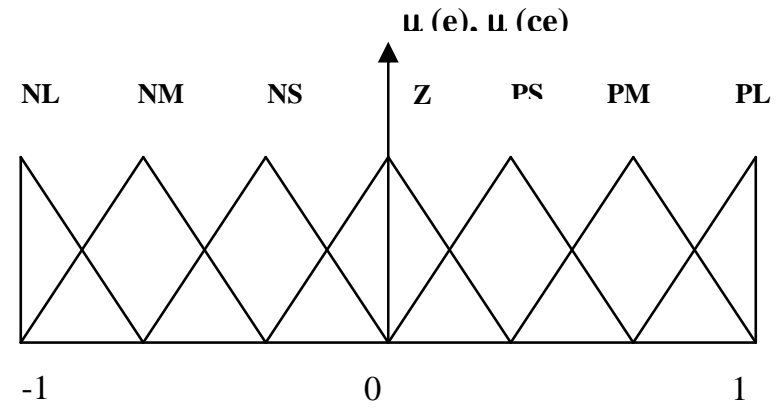

Fig. 5 membership functions of error change of error, and

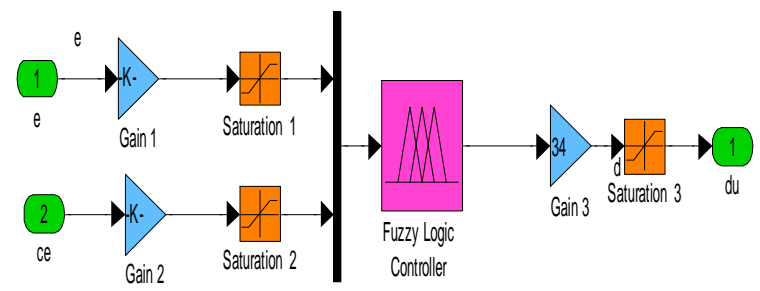

Fig. 6 AFLC architecture.

\section{B. NNC system design}

On the other hand the proposed NN control after many trials, shown in Fig.3, eventually employed three layers which are the input layer, hidden layer, and output layer. The input layer consists of three neurons which are the air temperature, pond temperature and error, hidden layer consists of seven neurons, and output layer of one neurons as shown in Fig. 7. The activation function used in this work is "logsig" for hidden layer, and "purelin" for output layer. The NNC is trained using a back propagation with Levenberg-Marquardt algorithm. The back propagation is a form of supervised learning for multi-layer nets. Error data at the output layer is back propagated to earlier ones, allowing incoming weights to these layers to be updated. It is most often used as training algorithm in current neural network applications. Figure 8 presents the mean square error between the network output and the target. The network response analysis is depicted in Fig. 9. As shown in this figure the regression " $\mathrm{R}$ " equal one which means that the output tracks the target in a correct way. 


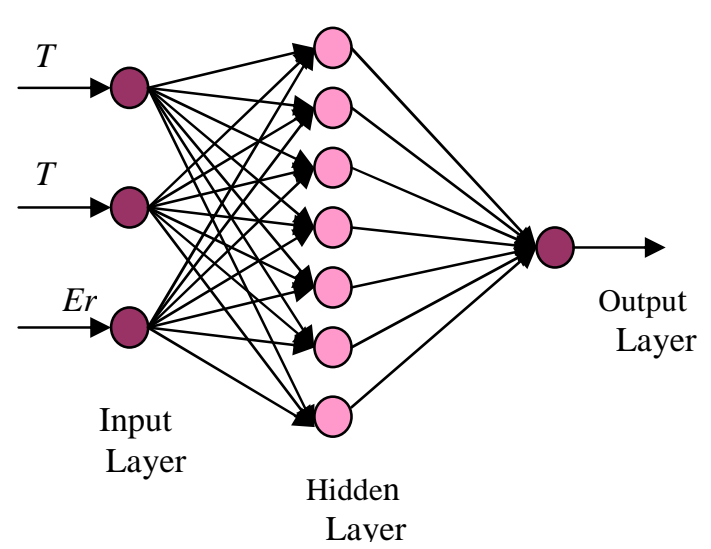

Fig. 7 Neural network controller architecture.

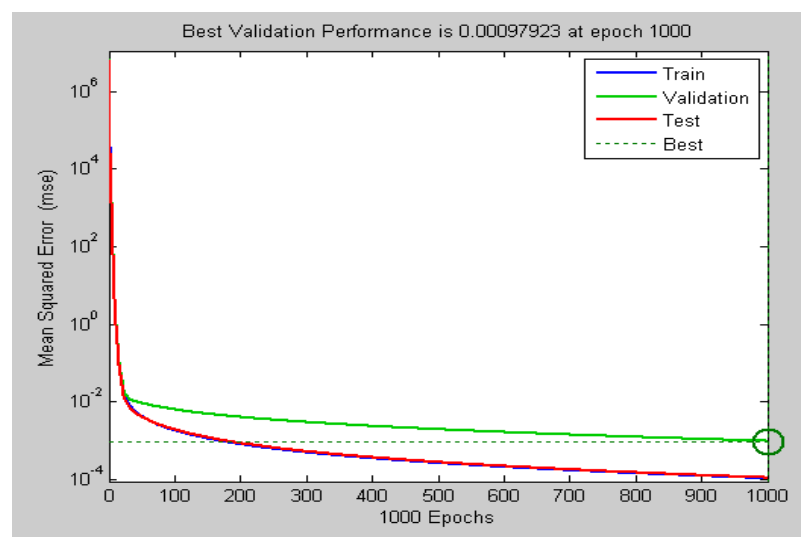

Fig. 8 Mean square error

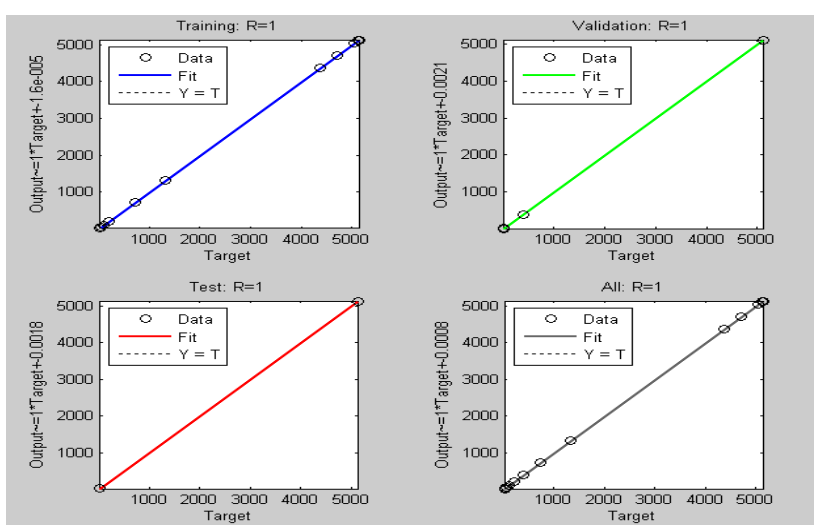

Fig. 9 Regression between the network output and target.

\section{System Simulation Using MATLAB}

The simulation model of the proposed thermal system using AFLC and NNC is depicted in Fig. 10 and Fig. 11 respectively. The system consists of solar thermal subsystem to feed the system with the required hot water during the day, biogas subsystem is the auxiliary heater, pond subsystem, and finally the control subsystem.

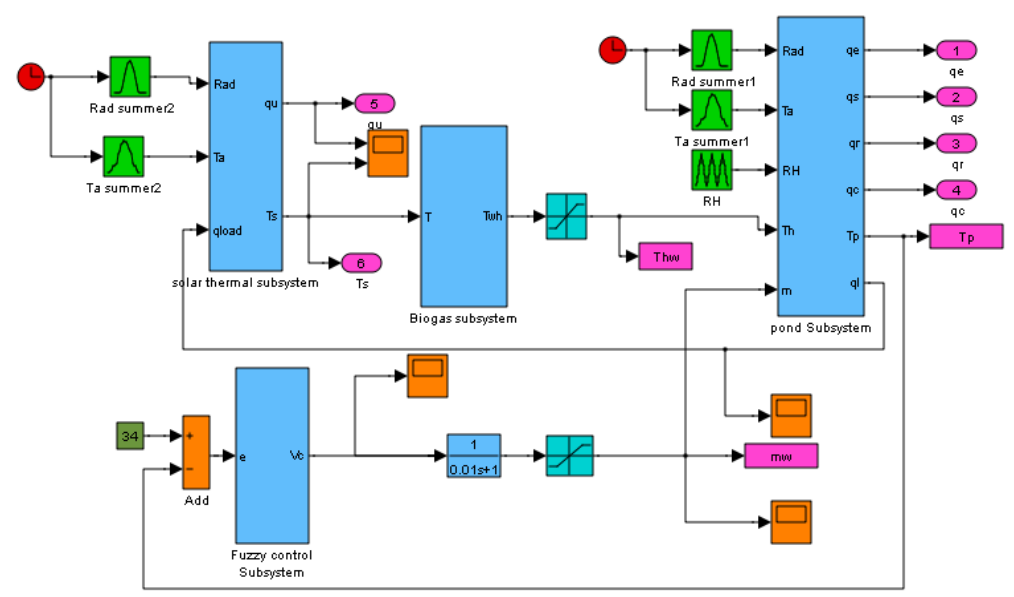

Fig. 10 Solar thermal system simulation with AFLC.

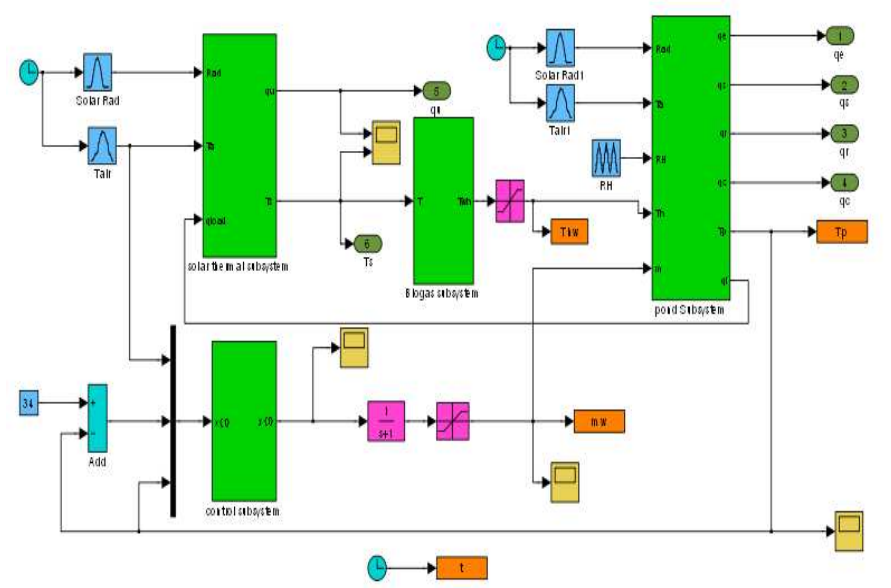

Fig. 11 Solar thermal system simulation with NNC.

\section{Simulation Results}

The results of the MATLAB software indicate the high capability of the proposed technique in controlling the water temperature in the aquaculture pond, even in case of changing atmospheric conditions. The system has two input parameters they are air temperature, and solar irradiance. Figure 12 and Fig. 13 represent solar irradiance in Mersa Matruh the site of consideration in summer and winter respectively. Figure 14 and Fig. 15 show the air temperature in summer and winter.

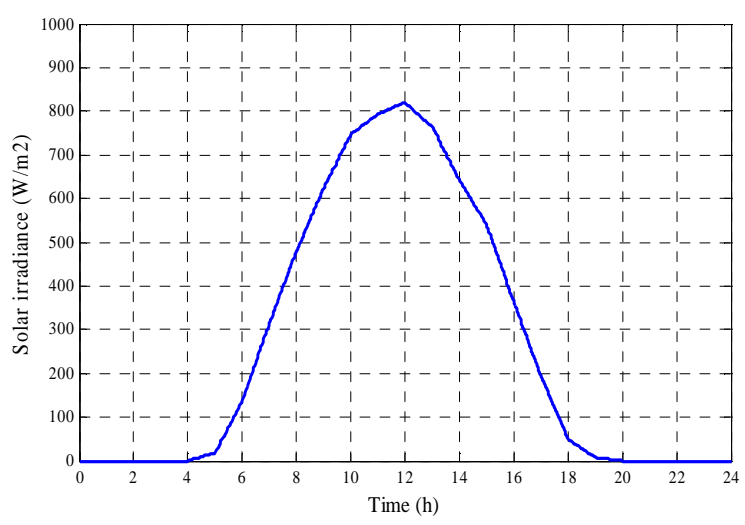

Fig. 12 Solar irradiance in summer. 


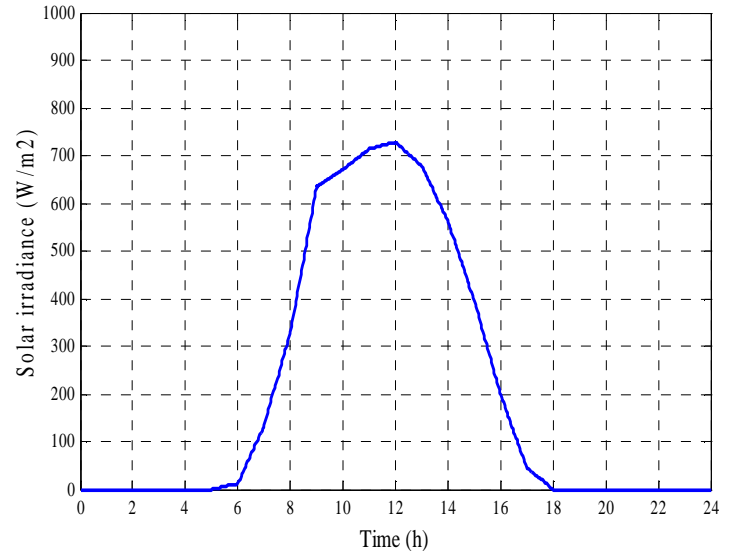

Fig. 13 Solar irradiance in winter.

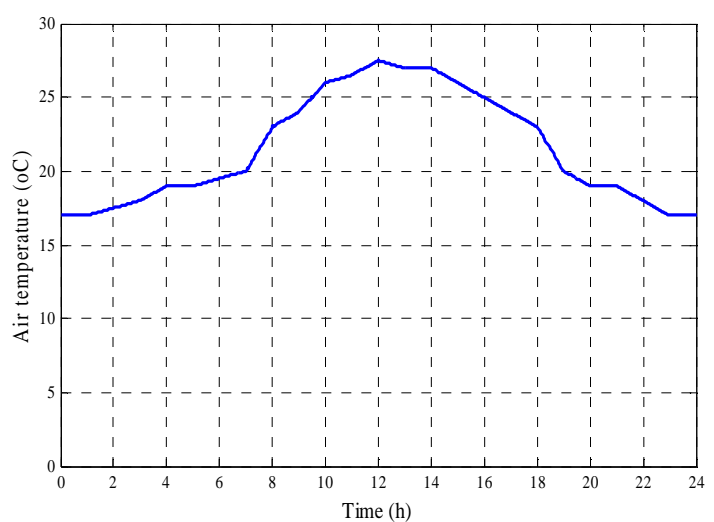

Fig. 14 Air temperature in summer.

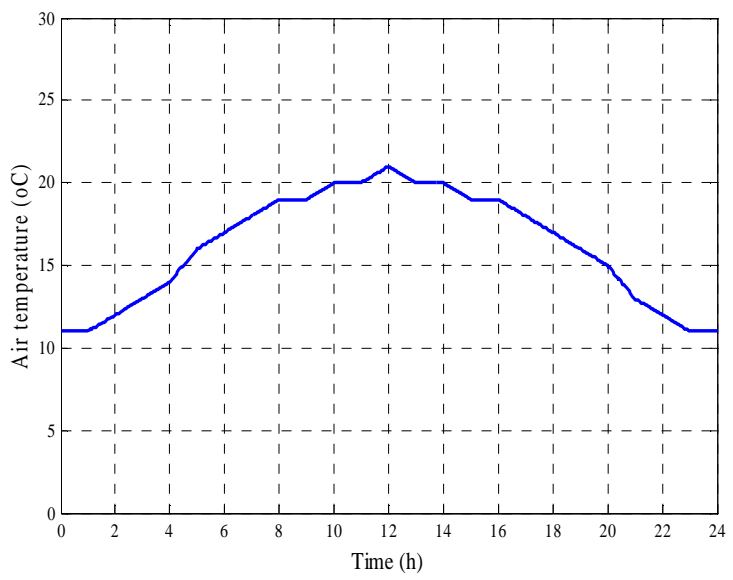

Fig.15 Air temperature in winter.

\section{A. AFLC results}

Figure 16 - and Fig. 17 indicate the pond temperature in summer and winter respectively. It is shown that the NN control has adjust the water temperature at $34^{\circ} \mathrm{C}$ without any variation during the day. Any variation in water temperature will harm the shrimp life, so the NN control has successes in this process.

Figure 18 - and Fig. 19 show the water flow rate variation over the day in summer and winter respectively. It is clear that as pond losses decrease the pond temperature increase, so the value of mass flow rate decreases. During the night hours the mass flow rate has high value rather than that the day hours. The mass flow rate in winter is higher than in summer because of low air temperature in winter than in summer. The simulation results show the high efficiency of the proposed control system for control pond water temperature.

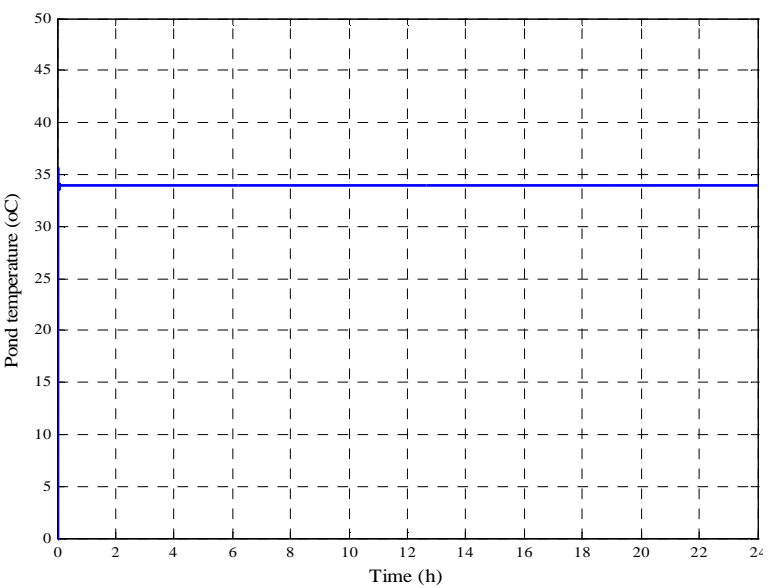

Fig.16 Pond temperature $\left({ }^{\circ} \mathrm{C}\right)$ in summer.

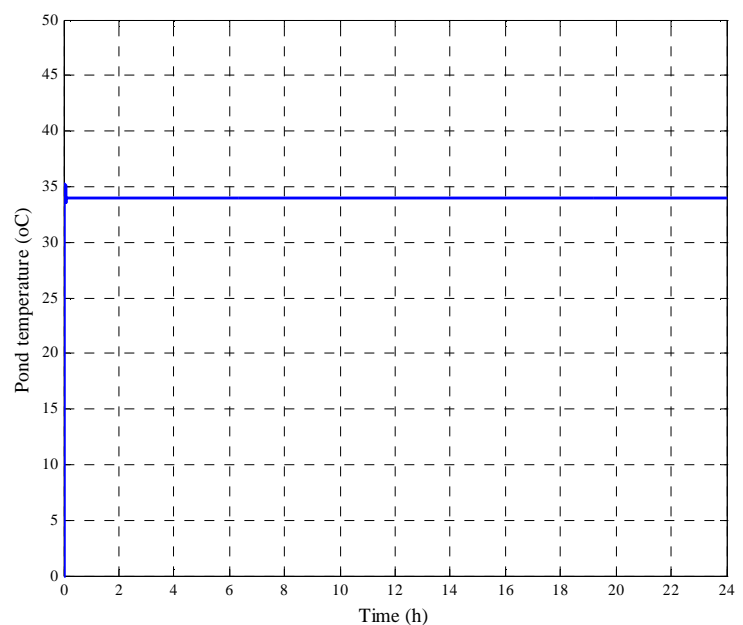

Fig. 17 Pond temperature $\left({ }^{\circ} \mathrm{C}\right)$ in winter.

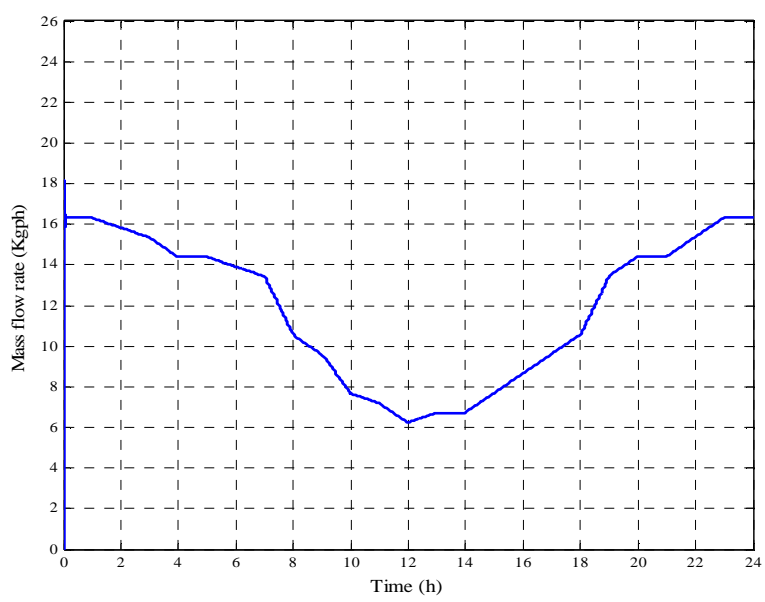

Fig. 18 mass flow rate in summer. 


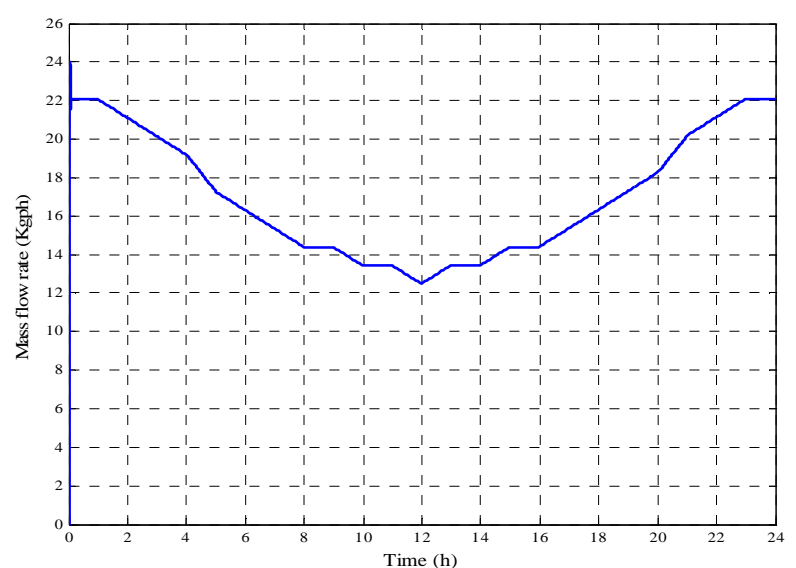

Fig.19 mass flow rate in winter.

\section{B. NNC results}

Figure 20 and Fig. 21 indicate the pond temperature in summer and winter respectively. It is shown that the $\mathrm{NN}$ control has adjust the water temperature at $34^{\circ} \mathrm{C}$ without any variation during the day. Any variation in water temperature will harm the shrimp life, so the NN control has successes in this process.

Figure 22 and Fig. 23 show the hot water flow rate variation over the day in summer and winter respectively.

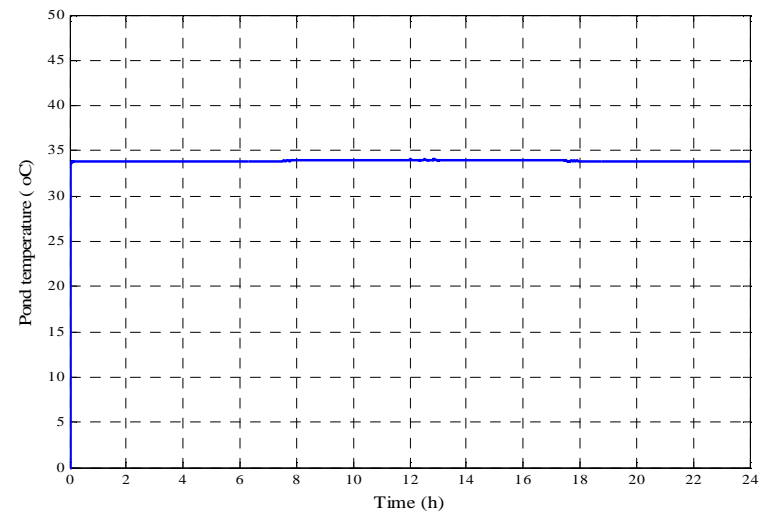

Fig.20 Pond temperature $\left({ }^{\circ} \mathrm{C}\right)$ in summer.

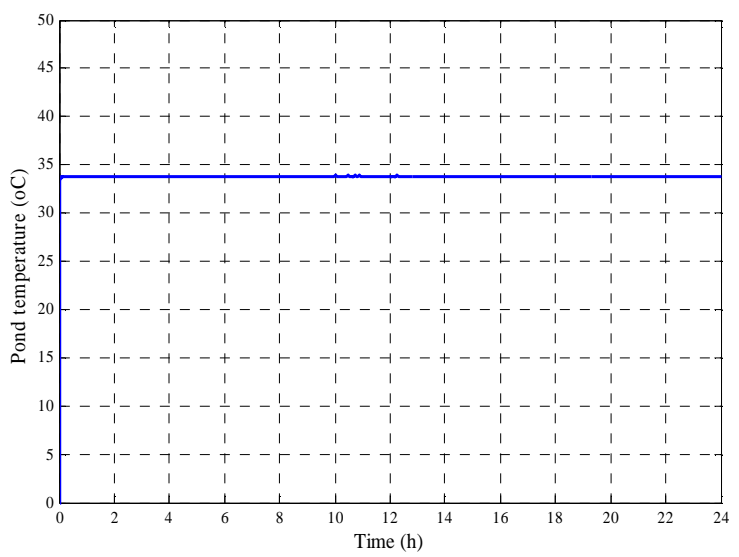

Fig. 21 Pond temperature $\left({ }^{\circ} \mathrm{C}\right)$ in winter.

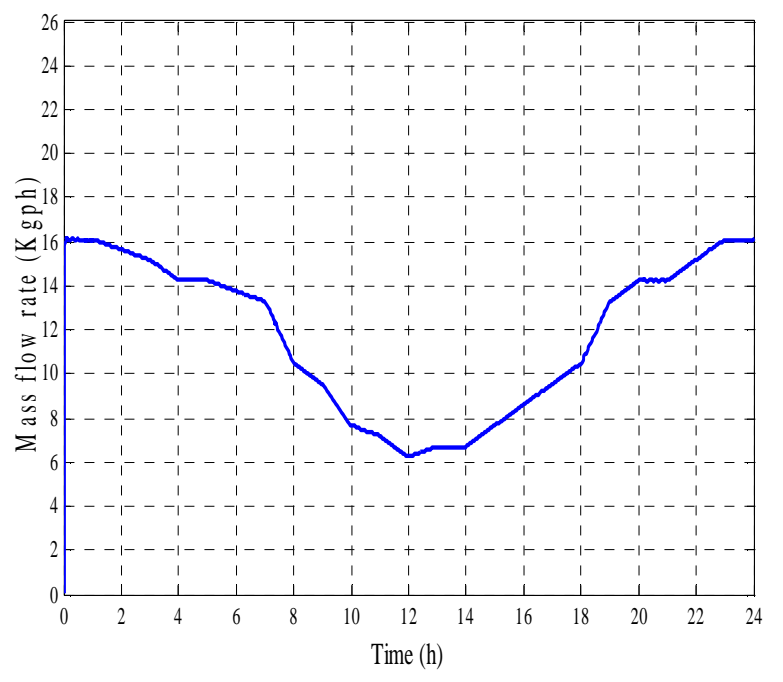

Fig. 22 mass flow rate in summer.

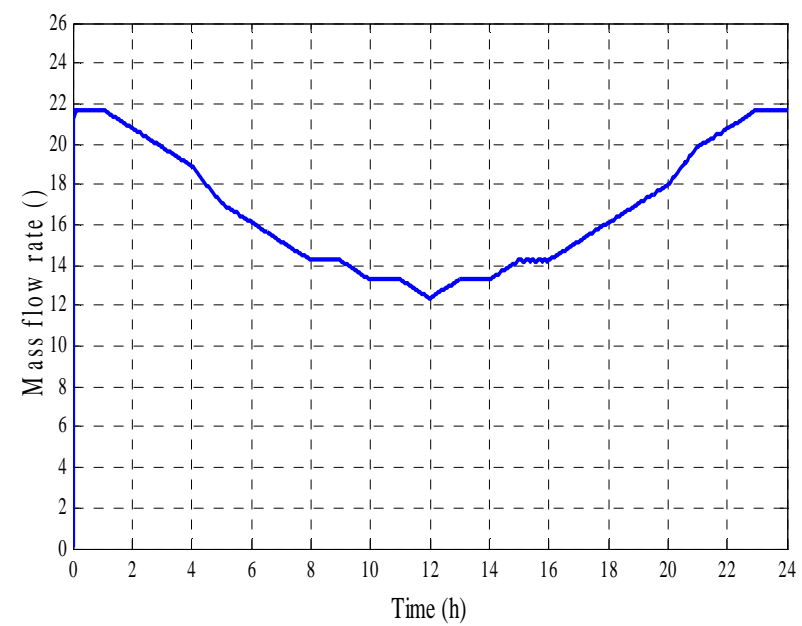

Fig. 23 mass flow rate in winter.

\section{Comparison between AFLC and NNC}

From the pervious output signals of the two controls, the NNC has several inputs which are air temperature, pond temperature, and error signal. These inputs aid in adjust the output signal of the control more accurate. The pond temperature takes very small time to be constant at $34^{\circ} \mathrm{C}$. AFLC has error and change of error as input signal only. The output adjusts the pond temperature at $34^{\circ} \mathrm{C}$ but after a few seconds larger than NNC. The pond temperature has increase to $36^{\circ} \mathrm{C}$ and then adjusted at $34^{\circ} \mathrm{C}$, which may be harmful for aquaculture life for a few seconds as depicted in Fig. 24 and Fig. 25 in summer and winter respectively. So from the pervious analysis NNC is better than AFLC. 


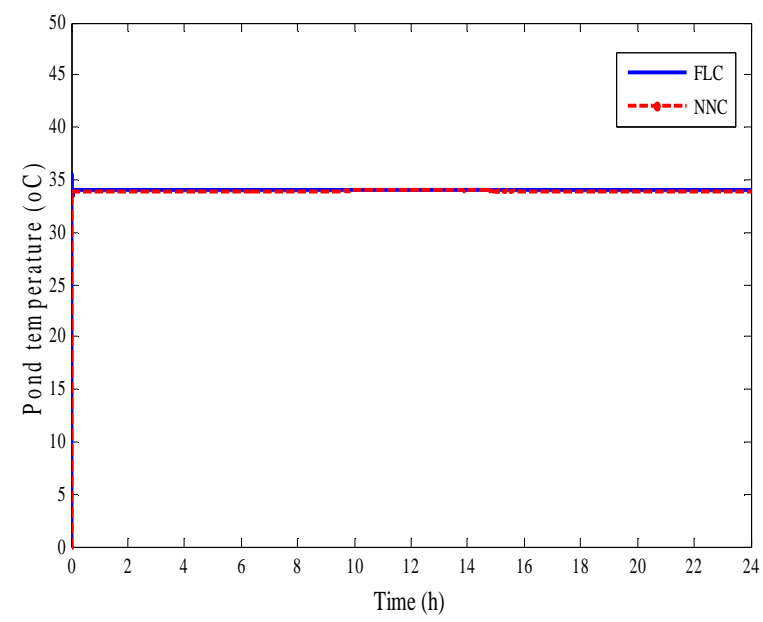

Fig.24 Pond temperature (oC) with NNC and FLC over the simulation period in summer.

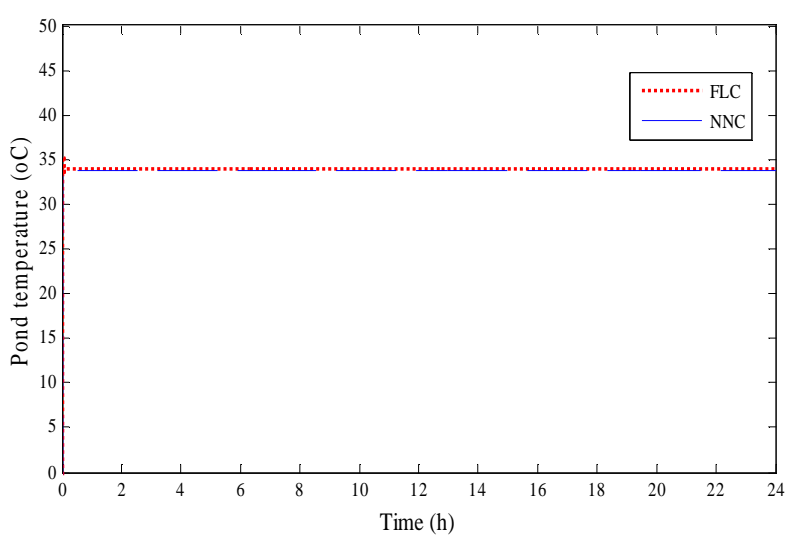

Fig.25 Pond temperature (oC) with NNC and FLC over the simulation period in winter.

\section{Conclusion}

The most important parameters to be monitored and controlled in an aquaculture system are related to water quality, since they directly affect animal health. In this paper, a complete mathematical modeling and MATLAB SIMULINK model for the solar thermal aquaculture water heating system are developed and a control system, which includes either the NNC or the AFLC controller, is developed for controlling water temperature.

Neural networks offer one such method with their ability to map complex nonlinear functions. The air temperature, pond temperature, and error are used as inputs to NN control. Offline training are applied with the BP algorithm has been used. The simulation results show that the feasibility of $\mathrm{NN}$ control in keeping water temperature constant at the desired degree $\left(34^{\circ} \mathrm{C}\right)$ by adjust the mass flow rate of hot water to the pond. AFLC with the three main components; Fuzzification, fuzzy rule base, and Defuzzification are introduced also and applied to control hot water flow rate.

The performance of the system is evaluated by comparing the performance of the system using NNC and AFLC. The response of output generation using $\mathrm{NNC}$ is more accurate and better than using AFLC.

\section{REFERENCES}

[1] Xiaojing Shena, Ming Chena, Jiang Yub, "Water Environment Monitoring System Based on Neural Networks for Shrimp Cultivation," In proc. Of IEEE International Conference on Artificial Intelligence and Computational Intelligence, 2009.

[2] Phillip G. Lee, "Process control and artificial intelligence software for aquaculture", Aquacultural Engineering Vol., 23, PP., 13-36, 2000.

[3] S.A. Kalogeria, "Applications of artificial neural networks in energy systems A review", Energy Conversion \& Management, Vol., 40, PP., 1073-1087, 1999.

[4] Jin Woo Moon, Sung Kwon Jung, and Jong-Jin Kim, "application of ann (artificial-neural-network) in residential thermal control", building and simulation, in proc of Eleventh International IBPSA Conference Glasgow, Scotland , 2009.

[5] Hossein Mirinejad, Seyed Hossein Sadati, Maryam Ghasemian and Hamid Torab, "control techniques in heating, ventilating and air conditioning (hvac) systems" Journal of Computer Science Vol., 4 (9), PP., 777-783, 2008.

[6] Govind N. Kulkarni, Shireesh B. Kedare, Santanu Bandyopadhyay, "Determination of design space and optimization of solar water heating systems," Solar Energy, Vol. 81, PP. 958-968, 2007.

[7] John Gelegenis a, Paschalis Dalabakis b, Andreas Ilias, " Heating of a fish wintering pond using low-temperature geothermal fluids, Porto Lagos, Greece," Geothermics, Vol. 35, PP. 87-103, 2006.

[8] Duffie, J., Beckman, W., Solar Engineering of Thermal Processes, second ed. John Wiley \& Sons Interscience, NewYork, 1991.

[9]M. Azouz, A. Shaltout and M. A. L. Elshafei, "Fuzzy Logic Control of Wind Energy Systems "Proceedings of the 14th International Middle East Power Systems Conference (MEPCON'10), Cairo Univ., Egypt, December 19-21, 2010.

[10] S. Lalouni, D. Rekioua, T. Rekioua and E. Matagne, "Fuzzy Logic Control of Stand-Alone Photovoltaic System with Battery Storage", Journal of Power Sources, Vol. 193, PP. 899-907, 2009.

[11] Ch. Ben Salah, M. Chaaben, M. Ben Ammar, "Multicriteria Fuzzy Algorithm for Energy Management of a Domestic Photovoltaic Panel", Renewable Energy Vol. 33, PP. 993 -1001, 2008.

[12] Soteris A Kalogiroua, Soa Pantelioub, Argiris Dentsoras, "Artificial neural networks used for the performance prediction of a thermosiphon solar water heater", Renewable Energy, Vol., 18, PP., 87-99, 1999.

[13] James A. Freeman, David M. Skapura, Neural Networks Algorithms, Applications, And Programming Techniques, Addison-Wesley Publishing Company, Inc., Paris, 1991.

[14] M.N. Cirstea, A. Dinu, J.G. Khor, M. McCormick, "Neural and Fuzzy Logic Control of Drives and Power Systems", Replika Press Delhi, India, 2002.

[15] Soteris A. Kalogirou, "Prediction of flat-plate collector performance parameters using artificial neural networks", Solar Energy, Vol., 80, PP., 248-259, 2006.

[16] Adnan Sozen, Tayfun Menlik, Sinan Unvar, "Determination of efficiency of flat-plate solar collectors using neural network approach", Expert Systems with Applications, Vol., 35, PP., 1533-1539, 2008. 